Research Paper

\title{
Early Integration of Palliative Care in Oncology Practice: Results of the Italian Association of Medical Oncology (AIOM) Survey
}

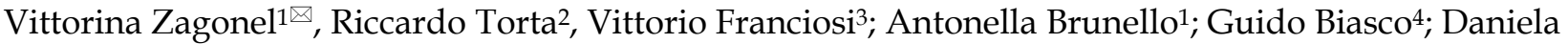

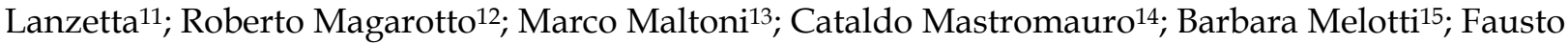 \\ Meriggi16; Ida Pavese ${ }^{17}$; Erico Piva18; Cosimo Sacco ${ }^{19}$; Giuseppe Tonini ${ }^{20}$; Leonardo Trentin ${ }^{21}$; Paola \\ Ermacora ${ }^{19}$; Antonella Varetto ${ }^{2}$; Federica Merlin ${ }^{22}$; Stefania Gori2 ${ }^{23}$; Stefano Cascinu ${ }^{24}$; Carmine Pinto ${ }^{25}$; \\ AIOM Simultaneous \& Continuous Care (SCC) Task Force-ESMO-DCs

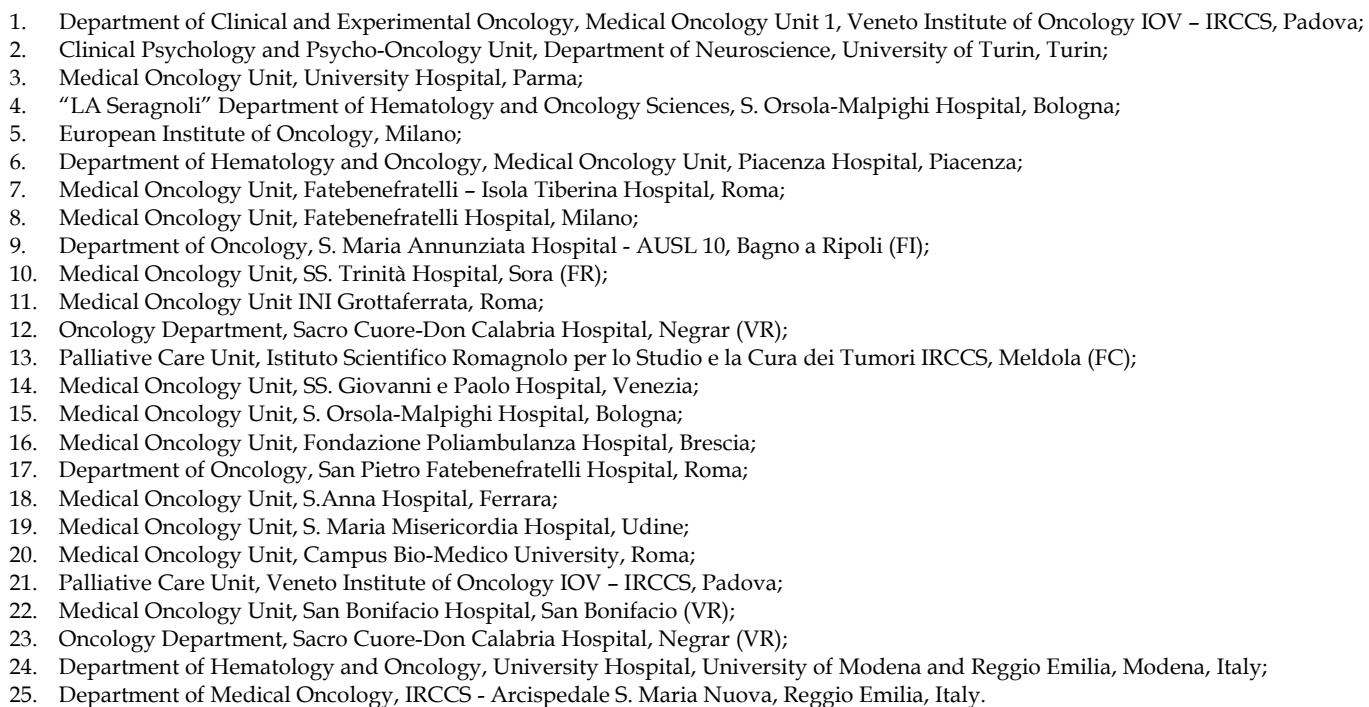
Cattaneo5; Luigi Cavanna6; Domenico Corsi 7 ; Gabriella Farina ${ }^{8}$; Luisa Fioretto9; Teresa Gamucci10; Gaetano

$\triangle$ Corresponding author: Vittorina Zagonel, MD. Department of Clinical and Experimental Oncology, Medical Oncology Unit 1 , Veneto Institute of Oncology IOV - IRCCS, via Gattamelata 64, 35128 Padua, Italy. tel + 390498215910 - fax +390498215900 e-mail: vittorina.zagonel@ioveneto.it.

(C) Ivyspring International Publisher. Reproduction is permitted for personal, noncommercial use, provided that the article is in whole, unmodified, and properly cited. See http://ivyspring.com/terms for terms and conditions.

Received: 2015.12.08; Accepted: 2016.05.21; Published: 2016.09.27

\begin{abstract}
Background: Early integration of palliative care in oncology practice ("simultaneous care", SC) has been shown to provide better care resulting in improved quality-of-life and also survival. We evaluated the opinions of Italian Association of Medical Oncology (AIOM) members. Patients and methods: A 37-item questionnaire was delivered to 1119 AIOM members. Main areas covered were: social, ethical, relational aspects of disease and communication, training, research, organizational and management models in SC. Three open questions explored the definition of Quality of Life, Medical Oncologist and Palliative Care. Results: Four hundred and forty-nine (40.1\%) medical oncologists returned the questionnaires. Forty-nine percent stated they address non-curability when giving a diagnosis of metastatic tumor, and $43 \%$ give the information only to patients who clearly ask for it. Fifty-five percent say the main formative activity in palliative medicine came from attending meetings and $90 \%$ agree that specific palliative care training should be part of the core curriculum in oncology. Twenty-two percent stated they consulted guidelines
\end{abstract}


for symptom management, $45 \%$ relied upon personal experience and $26 \%$ make a referral to a palliative care specialist. Seventy-four percent were in favor of more research in palliative medicine. An integration between Units of Oncology and Palliative Care Services early in the course of advanced disease was advocated by $86 \%$. Diverse and multifaceted definitions were given for the concepts of Quality of Life, Palliative Care and Medical Oncologist. Conclusion: SC is felt as an important task, as well as training of medical oncologists in symptom management and research in this field.

Key words: early palliative care, simultaneous care, medical oncology, advanced cancer, research.

\section{Introduction}

In 1998, ASCO published a special article outlining the importance of palliative care in the cancer care continuum (1), in which statements were made that it was the oncologist's responsibility to care for the patient's needs from diagnosis through the continuum that included end-of-life care. Since then, there has been an increasing availability of palliative medicine services, and the question has arisen whether palliative medicine services delivered in conjunction with oncology services (Simultaneous Care, SC) provide added value to patients, families, and physicians. In fact, along with availability of palliative care services, evidence has mounted that this integrated approach provides benefits in all the quality-of-life parameters (2), including ensuring the proper setting of care at the end of life, improving patient satisfaction, and a reduction of costs as a consequence of limited inappropriate use of chemotherapy in the last months of life $(3 ; 4)$.

The European Society for Medical Oncology (ESMO) since 2003 has been leading the way by formally recognizing Designated Centers of Integrated Oncology and Palliative Care (ESMO-DCs) (5), and SC is thus considered the paradigm of best care for patients with symptomatic advanced cancer by both ASCO and ESMO.

The Italian Association of Medical Oncology (AIOM) itself, since 2008 has set up a task force called "Simultaneous and Continuous Care (SCC)" which includes the representatives of the Italian ESMO-DCs. The goals of SCC task force were: 1 . To train medical oncologists in palliative medicine, 2 . To spread the culture of integration between oncologists and palliative care specialists, 3. To compare organizational models with the aim to promote the application of SC, and 4. To facilitate Oncology Units become ESMO-DC (6).

From 2003 to 2014, forty Italian Medical Oncology Units became ESMO-DCs, ranking first in Europe, and heads of each new DC have become part of the AIOM SCC task force.

Despite the evidence of the benefit of the integration of early palliative care in the trajectory of cancer patients, moving from why to how, SC requires a cultural change of oncologists. Yet, a global consensus with regard to the best organizational model is currently lacking (7).

The acquisition of the actual picture of how oncologists have implemented the SC in clinical practice is felt as a necessary preliminary step for further suggestion of possible education and organizational improvement. This survey aimed to collect descriptive data regarding the practice and attitudes of Italian oncologists in relation to early palliative care management of patients with advanced cancer, and oncologist-related barriers to the provision of optimal SC.

\section{Methods}

A web-based questionnaire was developed within a focus group by members of AIOM SCC task force on the basis of the main aspects needed to achieve SC in clinical practice, and debated in the literature from the position of the leading oncology (ASCO and ESMO in particular). The questionnaire was accompanied by $4-5$ selected papers for each one of the four main covered areas (listed in Supplementary Material S1). The tool was reviewed by oncologists within the task force and the executives of AIOM for content validity. The final version of the 37-item questionnaire was sent by e-mail to all 1119 AIOM members, who were asked to anonymously answer to the questions, stating the answers would have been used to set up the bases for a subsequent consensus conference.

Given the absence of any patient-related data, no Ethics Committee approval was required according to Italian National regulations. A privacy statement was provided to every responding oncologist.

Beyond the first set of questions regarding the evaluation of age, sex, number of years in the practice of medical oncology, and the workplace (Comprehensive Cancer Center, University Hospital, Public Health Facility or Private Hospitals), the main pool of questions was classified into four domains considered as major aspects for SC: 1. Social, ethical, relational aspects of disease and communication (PART A, Q1-6); 2. Training (PART B, Q1-8); 3. 
Research (PART C, Q 1-7) and 4. Organizational models (PART D, Q1-6).

The questionnaire also involved three open questions (OQ) which dealt with the most appropriate definition of Quality of Life (OQ1), of Medical Oncologist (OQ2) and of Palliative Care (OQ3).

The data entry was done by AIOM and descriptive statistics of the data were performed used Microsoft Office Excel ${ }^{\odot}$ software, 2010. Comparisons between categorical variables were studied by means of the Pearson's chi-squared test using the IBM SPSS Statistics for Windows, Version 22.0. Armonk, NY: IBM Corp.

\section{Results}

Between March and July 2013, four hundred forty-nine medical oncologists (40.1\% of the members) completed and returned the anonymous questionnaires. This is a good percentage, considering that other AIOM surveys got far less respondents (ranging from 20 to $30 \%$ ). Summary statistics for socio-demographic variables are reported in Table 1.

Table 1: Frequency distribution of responses to the questionnaire

\begin{tabular}{|c|c|c|}
\hline & $\begin{array}{l}\text { No. of } \\
\text { responders }\end{array}$ & $\%$ \\
\hline \multicolumn{3}{|l|}{ Sex } \\
\hline Male & 240 & 53 \\
\hline Female & 209 & 47 \\
\hline Total & 449 & \\
\hline \multicolumn{3}{|l|}{ Age } \\
\hline $24-35$ & 93 & 21 \\
\hline $36-45$ & 91 & 20 \\
\hline$>45$ & 265 & 59 \\
\hline NA & & \\
\hline \multicolumn{3}{|l|}{ Geographic distribution } \\
\hline North & 245 & 55 \\
\hline Centre & 123 & 27 \\
\hline South/Islands & 81 & 18 \\
\hline \multicolumn{3}{|l|}{ Place of work } \\
\hline Hospital - Local Health Social Unit & 298 & 66 \\
\hline University Hospital & 53 & 12 \\
\hline Comprehensive Cancer Center (IRCCS) & 53 & 12 \\
\hline Private Hospital & 29 & 6 \\
\hline Other & 16 & 4 \\
\hline \multicolumn{3}{|l|}{ Type of Oncology Unit } \\
\hline With own beds & 305 & 68 \\
\hline With beds in common with other Services & 38 & 8 \\
\hline No beds, only Day Hospital/Day Clinic & 106 & 24 \\
\hline \multicolumn{3}{|l|}{ Years of activity as oncologist } \\
\hline$<10$ & 118 & 26 \\
\hline $10-20$ & 131 & 29 \\
\hline$\geq 20$ & 200 & 45 \\
\hline \multicolumn{3}{|l|}{ Palliative Care Service at the workplace Hospital } \\
\hline There is availability of a Palliative Care Service & 162 & 36 \\
\hline There is availability of Pain Relief Unit & 171 & 38 \\
\hline $\begin{array}{l}\text { Palliative Care is provided inside the Oncology } \\
\text { Unit }\end{array}$ & 63 & 14 \\
\hline A referral is made to community-based services & 53 & 12 \\
\hline
\end{tabular}

Even if a drop out analysis is not possible in a web-based survey, the sample can be assumed to be quite representative of AIOM members as for socio-demographic distribution.

Almost $60 \%$ of participants are older than 45 years, and $45 \%$ reported working in oncology for more than 20 years. The geographical distribution, sex and place of work are in line with the distribution in Italy of the structures of oncology. Sixty-eight percent of respondents work in oncology units with beds. The distribution of the frequency of answers to the questionnaires are fully reported in Tables 2-5 respectively for questionnaire parts A, B, C, D. Selected answers are described here, and grouped into the four major domains reported above.

\section{A. Ethical, cultural and relational aspects of cancer and implications for patient communication (Table 2)}

Forty-nine percent of the responding oncologists stated they introduce the aspect of non-curability when giving a diagnosis of metastatic tumor (Question A1) and 43\% state they give the information only to those patients who clearly ask for that. A few oncologists $(8 \%)$ generally do not give such information. As for end-of-life decisions, $49 \%$ of the oncologists state they sometimes discuss patients' wishes at the time of the communication of the diagnosis and prognosis, whereas 33\% of them generally do not verify end-of-life directives. Family requests, in all cases in which patients do not directly ask for information, are taken into account from overall $84 \%$ of oncologists, whereas $15 \%$ state they do not acquiesce to relatives asking not to discuss prognosis with the patients.

Oncologists who prescribe more than 2 lines of anticancer treatments declare to do so in order to palliate cancer symptoms (50\%), to respond to the need of patients and their families $(19 \%)$ and to continue some form of treatment (14\%).

\section{B. The medical oncologist training in palliative medicine (Table 3)}

Fifty-five percent of the participants said their main formative activity in the last year in palliative medicine came from attending meetings, and for twenty-two percent no educational activity had been carried out in the last year (Question B1). Ninety percent of the participants strongly agree that specific training in palliative medicine should be an integral part of the core curriculum in oncology (Question B2). Tests for quality-of-life and symptoms management are commonly used by $20 \%$ of the participants, whereas $75 \%$ of them only used such tests if required by clinical trials or in some cases outside clinical trials 
(Question B4). Sixty-nine percent of the participants completely agree that SC should be offered by the Units of Medical Oncology, whereas 7\% stated they did not agree or that the issue was unclear (Question B7).

Table 2: Ethical, cultural and relational aspects of cancer and implications for patient communication (Part A)

N. respondents \%

A1 When disclosing a diagnosis of

metastatic cancer to a patient do you

also inform about non-curability?

Yes, always

Yes, only if patients ask

Generally no

Never

The so-called "patient-centered care" requires that the patient can decide on therapeutic and assistential strategies: do you agree?

Yes

No

I don't know

A3 When communicating a diagnosis of incurable cancer, do you verify patient's will on possible end-of-life directives?

Yes

Sometimes

No

A4 When disclosing prognosis, if the patient does not specifically ask for information, do you think family's requests should be taken into account (i.e. relative may ask not to disclose prognostic information)?

Yes, always

Yes, sometimes

No

I don't know

A5 In a patient with biliary duct carcinoma who ha metastatic disease at diagnosis, how many line of chemotherapy do you usually prescribe?

At least one

At least two

Three or more

Generally no chemotherapy

49

The prescription of more than two lines

of chemotherapy is a result of the

necessity of:

Reducing disease symptoms $26850^{*} 60^{\wedge}$

Delaying communication of prognosis $17 \quad 3 \quad 4$

Answering to patient's and family's $\quad 104 \quad 19 \quad 23$

requests

Answering to the necessity of $\quad 74$

continuing care

None of the above

$\begin{array}{ll}294 & 75 \\ 85 & 22 \\ 0 & 0 \\ 12 & 3\end{array}$

Footnotes: * \% on total options; ${ }^{\wedge} \%$ on single options
Table 3: The medical oncologist training in palliative medicine (PART B)

\begin{tabular}{llll}
\hline & $\begin{array}{l}\text { N. } \\
\text { respondents }\end{array}$ & $\%$ \\
\hline B1 & $\begin{array}{ll}\text { Which training in palliative medicine have } \\
\text { you received in the last year? }\end{array}$ & & \\
Master & 22 & $4^{*} 5^{\wedge}$ \\
Course & 150 & 2833 \\
Meeting & 245 & 4655 \\
None & 115 & 2226
\end{tabular}

B2 Do you think that specific competence in palliative medicine should be part of the training of a medical oncologist?

Totally agree

Partially agree

Disagree

$\begin{array}{ll}351 & 90 \\ 40 & 10 \\ 0 & 0\end{array}$

B3 How much do you think you are able to evaluate and treat tumor-related physical symptoms (i.e. pain, dyspnea etc)?

$\begin{array}{lll}\text { A lot } & 104 & 29 \\ \text { Enough } & 265 & 66 \\ \text { A little } & 21 & 5 \\ \text { Not competent } & 1 & 0\end{array}$

B4 In your clinical practice do you use tests for patient's quality of life and symptom control? Yes, always (specifys)

Yes, only if required for clinical trials

Sometimes

Never

B5 How competent do you think you are in evaluating and treating psychological distress in cancer patients?

$\begin{array}{lll}\text { A lot } & 35 & 9 \\ \text { Enough } & 246 & 63 \\ \text { A little } & 108 & 28 \\ \text { Not competent } & 2 & 0\end{array}$

B6 Which definition of "simultaneous care" do you think is more appropriate?

Continuous care in the passage from 29 oncological treatment to palliative treatment Integration of expertise in order to grant $\quad 75$ proper control of symptoms

Early integration between oncological treatment and palliative care (symptom control)

B7 Do you think simultaneous care should be guaranteed by Medical Oncology Units?

Completely agree

Partially agree

Disagree

It depends

B8 Do you think AIOM has been committed to the training of Medical Oncologists in symptoms' control?

$\begin{array}{lll}\text { A lot } & 41 & 11 \\ \text { Enough } & 203 & 53 \\ \text { A little } & 132 & 32 \\ \text { I don't know } & 15 & 4\end{array}$

Footnotes: * \% on total options; $\wedge \%$ on single options

$\S$ Edmonton Symptom Assessment Scale (ESAS); Pain Visual Analogue Scale (VAS); Pain NRS; Pain VAS; ECOG Performance Status; EORTC QLQ30, PaP (Palliative Prognostic) score; FACT (Functional Assessment of Cancer Therapy); ADL (Activities of Daily Living); IADL (Instrumental Activities of Daily Living); Direct questions without specific tests on Pain, Dyspnea, Nausea/Vomiting; MMSE (Mini Mental State Examination); Only clinical assessment and/or vital signs; WHO scale for chemotherapy toxicity; Rotterdam checklist; Medical Oncology Unit-specific questionnaires; BPI (Brief Pain Inventory); CGA (Comprehensive Geriatric Assessment). 


\section{3 . The research on the integration between cancer treatments and palliative cares (Table 4)}

Seventy-four percent of the participants completely agreed that it is a task of the oncologists to carry out and participate in clinical trials for symptom management in cancer patient, whereas $25 \%$ only partially agreed with the statement (Question C1). Eighty-nine percent did not feel there was any ethical/psychological problem in consenting patients for participation in such trials (Question C2). In particular, oncologists felt that more research should be done in palliative medicine with regard to communication/relational aspects, symptom management, organizational and management issues, interrelation between active oncological treatment and palliative treatment $(23.9 \%, 24.2 \%, 20 \%, 31.5 \%$ respectively, Question C3).

Finally, in the management of symptoms in cancer patients, $22 \%$ of the participants stated they consulted guidelines, whereas $45 \%$ relied upon personal experience and $26 \%$ of them make a referral to a palliative care specialist.

Table 4: The research on the integration between cancer treatments and palliative cares (PART C).

\begin{tabular}{|c|c|c|c|c|}
\hline & & N. respondents & $\%$ & \\
\hline \multirow[t]{5}{*}{$\mathrm{C} 1$} & $\begin{array}{l}\text { Do you consider it to be the competence of medical oncologists to activate or participate in clinical } \\
\text { trials dealing with treatment of symptoms in cancer patients? }\end{array}$ & & & \\
\hline & Completely agree & 286 & 74 & \\
\hline & Partially agree & 99 & 25 & \\
\hline & Disagree & 4 & 1 & \\
\hline & I don't know & 0 & 0 & \\
\hline \multirow[t]{4}{*}{$\mathrm{C} 2$} & $\begin{array}{l}\text { Do you think there may be ethical or psychological issues in giving information and consenting } \\
\text { for clinical trials aimed at improving treatment of symptoms? }\end{array}$ & & & \\
\hline & No & 351 & 89 & \\
\hline & Yes (specify§s) & 14 & 4 & \\
\hline & I don't know & 26 & 7 & \\
\hline \multirow[t]{6}{*}{$\mathrm{C} 3$} & $\begin{array}{l}\text { Which areas of palliative medicine do you consider important for medical oncologists to invest in } \\
\text { research? }\end{array}$ & & & \\
\hline & Communication and relational aspects & 228 & $24^{*}$ & $51^{\wedge}$ \\
\hline & Treatment of symptoms & 231 & 24 & 51 \\
\hline & Organization and management models & 191 & 20 & 67 \\
\hline & Interrelation between oncological treatment and palliative care & 300 & 32 & 26 \\
\hline & None of the above & 3 & 0 & 1 \\
\hline \multirow[t]{6}{*}{$\mathrm{C} 4$} & $\begin{array}{l}\text { What do you think should be the principal objective of clinical research in patients with advanced } \\
\text { non-curable cancer? }\end{array}$ & & & \\
\hline & Improvement in overall survival & 58 & 15 & \\
\hline & Improvement in disease free survival & 15 & 4 & \\
\hline & Improvement in quality of life & 304 & 77 & \\
\hline & Cost reduction & 0 & 0 & \\
\hline & Other & 14 & 4 & \\
\hline \multirow[t]{6}{*}{ C5 } & Which is the definition of "clinical benefit" you consider most appropriate? & & & \\
\hline & Gain in disease-free survival & 22 & 5 & \\
\hline & Dimensional decrease of tumor & 4 & 1 & \\
\hline & Improvement in quality of life & 342 & 88 & \\
\hline & Pain reduction & 5 & 2 & \\
\hline & Other & 18 & 4 & \\
\hline \multirow[t]{6}{*}{ C6 } & In the choice of a palliative/symptomatic treatment of the oncological patient you rely on: & & & \\
\hline & Experience & 174 & 45 & \\
\hline & Advice of an expert in Palliative Care & 104 & 26 & \\
\hline & Consultation of guidelines & 87 & 22 & \\
\hline & Patients and their families & 8 & 2 & \\
\hline & Other & 18 & 4 & \\
\hline \multirow[t]{5}{*}{ C7 } & With regard to the trial by Temel et al (4), which are your considerations: & & & \\
\hline & The results are applicable only to NSCLC & 37 & 9 & \\
\hline & The results may be replicated in all tumor types & 221 & 57 & \\
\hline & Such results should change the practice in medical oncology & 116 & 29 & \\
\hline & Such results do not change the practice in medical oncology & 17 & 5 & \\
\hline
\end{tabular}

Footnotes: ${ }^{*} \%$ on total options; $\wedge \%$ on single options

$\S \S$ Positive bias for expectations; patients' awareness; difficulty in communication; difficulty in randomization; patients' cultural-background difficulties; should be palliative specialists' task; it's part of the oncologist's tasks; side effects and effective improvement of prognosis; overt and punctual communication of prognosis and difficulties of such disclosures to be accepted by EC; ethics problems in placebo use in terminally ill patients; patients' may associate palliative care use with terminal care; symptoms' care is usually felt as a "non-therapy" when it is the sole therapy used; fear of receiving "less-curative" treatment; poor understanding; fear of obtaining a consensus which is ethically valid for patients in poor general conditions; palliative sedation. 


\section{The organizational and management models for the realization of SC (Table 5)}

Eighty-six percent of the participants thought it is useful to integrate Units of Oncology and Palliative Care Units/Services early in the course of the advanced disease in order to provide a comprehensive patient care (Question D1). The model believed to be the most effective is Model $\mathrm{C}$ by Bruera (8), selected by $57 \%$ of the participants, Question D2), in which the unit of Medical Oncology accounts for oncological treatment, Palliative Care Unit manages the symptoms, and they are routinely interfaced within multidisciplinary meetings. Bruera models thought to be more feasible in the local hospitals were integrated care model $(36 \%)$, followed by congress practice model $(31 \%)$ and by solo practice model $(25 \%)$. For $8 \%$ of the participants, no model could be feasible in their hospitals (Question D3).

Sixty-three percent of the oncologists believed there should be a well-structured departmental integration between the Units of Oncology and Palliative Care Units / Services, while 34\% thought the cooperation could be guaranteed through periodic meetings and case discussion (Question D4).

The main issues in the interaction with the palliative care teams are thought to be those who deal with organizational aspects of case management, possibility of conflicts between professionals, the loss of a decision-making role, and the possibility of introducing elements of confusion for the patients (48\%, 20\%, 4\%, 16\%, respectively; Question D6).

Table 5: The organizational and management models for the realization of Simultaneous Care (PART D).

\begin{tabular}{|c|c|c|c|c|}
\hline & & N. respondents & $\%$ & \\
\hline \multirow[t]{5}{*}{ D1 } & $\begin{array}{l}\text { Do you think it may be useful to integrate Units of Oncology and Palliative Care } \\
\text { Services for a global care approach of the cancer patient? }\end{array}$ & & & \\
\hline & Yes, in an early phase of diagnosis of advanced disease & 340 & 86 & \\
\hline & Yes, but only in end-stage / terminal disease & 33 & 9 & \\
\hline & No & 9 & 2 & \\
\hline & I don't know & 9 & 3 & \\
\hline \multirow[t]{4}{*}{ D2 } & Which of these models proposed by Bruera (8) do you consider more effective? & & & \\
\hline & $\begin{array}{l}\text { Model A: the Medical Oncology Unit takes care of all patient-related issues, from the } \\
\text { oncological treatment to symptom control }\end{array}$ & 89 & 24 & \\
\hline & $\begin{array}{l}\text { Model B: the Medical Oncology Unit focuses on cancer assessment and treatment and } \\
\text { refers the patient to various subspecialties for other concerns (i.e. pneumologist for } \\
\text { dyspnea, anesthesiologist for pain management, psychiatrist for emotional distress, etc) }\end{array}$ & 74 & 19 & \\
\hline & $\begin{array}{l}\text { Model C: the Medical Oncology Unit focuses on cancer assessment and treatment and } \\
\text { collaborates with the palliative care team, which provides control of symptoms and } \\
\text { participates in multidisciplinary tumor boards }\end{array}$ & 228 & 57 & \\
\hline \multirow[t]{5}{*}{ D3 } & $\begin{array}{l}\text { Of the three model proposed by Bruera, which one is actuated or could be feasible in } \\
\text { your place of work? }\end{array}$ & & & \\
\hline & A & 94 & 25 & \\
\hline & B & 122 & 31 & \\
\hline & C & 144 & 36 & \\
\hline & None & 31 & 8 & \\
\hline \multirow[t]{5}{*}{ D4 } & $\begin{array}{l}\text { Do you think that the integration between the Units of Medical Oncology and Palliative } \\
\text { Care Services should take place in a structured way? }\end{array}$ & & & \\
\hline & Yes, through a departmental structured organization & 284 & 63 & \\
\hline & Yes, through regular meetings and case discussions & 154 & 34 & \\
\hline & No, it should take place on a spontaneous basis & 2 & 0 & \\
\hline & I don't know & 9 & 2 & \\
\hline \multirow[t]{6}{*}{ D5 } & $\begin{array}{l}\text { Which aspect of patient care do you think could improve through the integration } \\
\text { between Medical Oncology and Palliative Care Units/ Services? }\end{array}$ & & & \\
\hline & Caring for the patient in all patient-related issues & 281 & $42^{*}$ & $63^{\wedge}$ \\
\hline & Having more professionals to provide better quality of life for the patient & 216 & 32 & 48 \\
\hline & Deal more effectively with the issues of ending active treatment & 96 & 14 & 21 \\
\hline & Allows for a more effective delivery of oncological treatments & 80 & 12 & 18 \\
\hline & None of the above & 4 & 1 & 1 \\
\hline \multirow[t]{6}{*}{ D6 } & $\begin{array}{l}\text { What do you think may be the main critical issues with the palliative care team after } \\
\text { referral of the patient? }\end{array}$ & & & \\
\hline & $\begin{array}{l}\text { The organizational aspects for the management of the patient (periodical meetings, } \\
\text { contact only when needed etc) }\end{array}$ & 261 & $48^{*}$ & $58^{\wedge}$ \\
\hline & The possibility of conflicts between professionals & 108 & 20 & 24 \\
\hline & The loss of the main decisional role in therapeutic choices & 24 & 4 & 5 \\
\hline & The introduction of an element of confusion in the therapeutic path of the patient & 88 & 16 & 20 \\
\hline & None of the above & 63 & 12 & 14 \\
\hline
\end{tabular}

Footnotes: ${ }^{*} \%$ on total options; $\wedge \%$ on single options 


\section{Open questions}

The questionnaire also included three open questions regarding the description of the most appropriate definition of Quality of Life, of Medical Oncologist and of Palliative Care (OQ3). About half of the respondents $(242 / 449)$ also answered the three open questions. The predominant answer concerning medical oncologists' concept of Quality of Life (QoL) involved the wellbeing related to patient's dignity and to her/his abilities preservations (29\%) and, in descending order, to the subjective feeling of wellbeing $(20 \%)$ and to a joint perception of a physical, psychological and socioeconomic comfort (19\%). A wellbeing only related to physical and psychological parameters was the definition given by $19 \%$ of oncologists. A minority $(2 \%)$ defined QoL as related to only either physical, psychological, socio-economic and spiritual wellbeing (Fig.1).

The second open question regarded the definition of Medical Oncologist. The predominant one was related to a perceived full competence in cancer disease, from prevention to recovery or exitus of the patient $(36 \%)$. The second characterization was of a specialist with mainly internal medicine competence $(17 \%)$. Another group of answers included non-specific definitions (14\%) with generic or tautological answers such as "specialist in medical oncology". The residual definitions had a focus on specific kinds of competences: treating cancer patients $(13 \%)$, ability in coordination of oncologic and palliative care $(8 \%)$, specific expertise in collaboration with other specialists $(7 \%)$, or having competence including, but not limited to, chemotherapy management (4\%) (Fig.2).

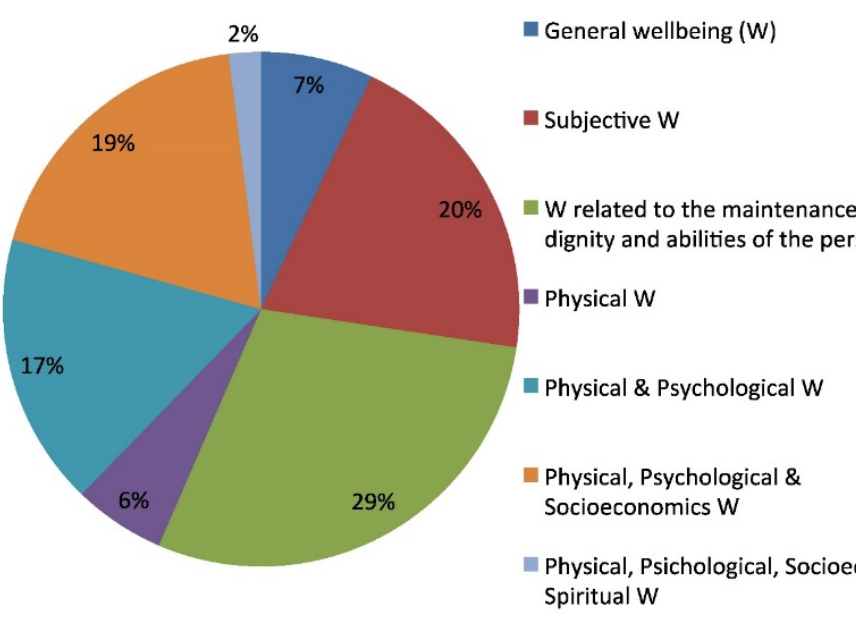

Figure 1. Quality of life definition.

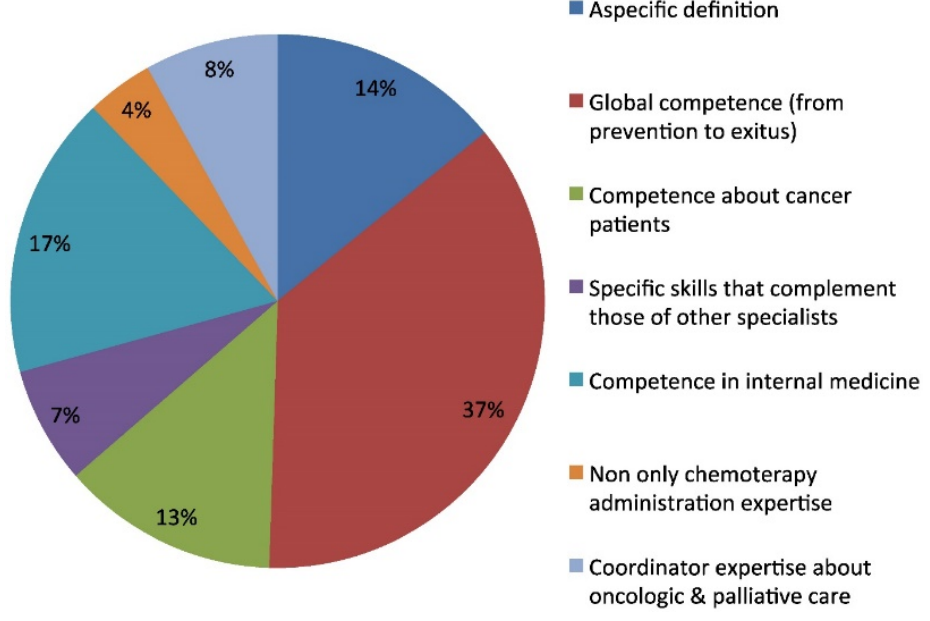

Figure 2: Medical oncologist definition.

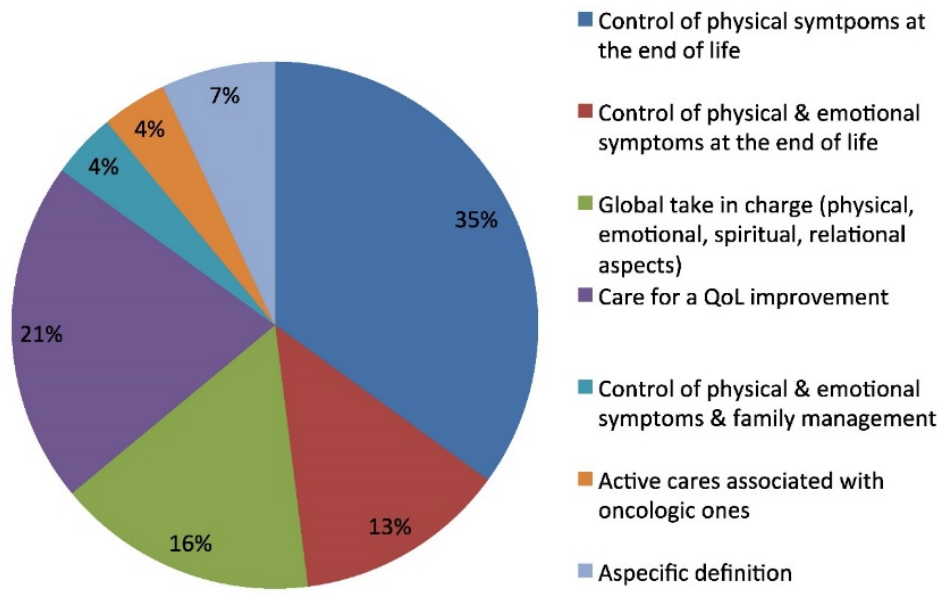

Figure 3: Palliative Care definition.

The third open question regarded the concept of palliative care. The prevalent definition reported was that of a discipline for the control of the physical symptoms at the end of life (35\%), of the physical and psychological symptoms altogether $(13 \%)$, and for quality of life improvement $(21 \%)$. Sixteen per cent of the responders considered palliative care as a global intervention for the control of physical, emotional, spiritual and relational problems of the patient. The definition also included taking charge of family for a $4 \%$ of oncologists and the same percentage emphasized the definition of palliative care as a kind of active care associated at earlier stages with oncologic active treatment (Fig.3). Some differences were found in the answers to three open questions, according to sex, age, and geographic areas, and length of medical service. These differences are outlined below.

Gender. No significant difference was observed in the answers given to three open questions. Generally, there was a higher prevalence of female oncologists giving a definition of QoL as wellbeing 
related to dignity and competence maintenance (median 29\%, women $34 \%$ vs men $24 \%$ ) yet not statistically significant. Similarly, a higher percentage of women gave a definition of QoL as physical wellbeing (median $6 \%$ : women $8 \%$ vs men $4 \%$ ), again statistically not significant.

Geographic areas. As for the definitions given according to geographic areas, a significant difference was observed in the definition of medical oncologist. In northern areas, oncologists self-attribute high competences in team collaboration (northern 10\% vs southern 5\%), while oncologists working in southern regions felt they are the coordinator of oncologic and palliative care (southern $13 \%$ vs northern $4 \%$, $\mathrm{p}=0.035$ ). No significant differences were observed as for the definition of QoL and of palliative care.

Length of medical service. No significant difference was observed for the definitions of QoL, medical oncologist and palliative care according to length of medical service. Yet, globally there was a higher prevalence of definition of QoL as subjective wellbeing, concurring with a care approach more tailored to the individual in his/her entirety than only to physical aspects of the disease among older oncologists (subjective wellbeing: median 20\%; oncologists with length of medical service $>20$ yrs: $27 \%$ vs $<10$ yrs 13\%). Also, with regard to the definition of medical oncologist, younger specialists more likely reported they have competences in multidisciplinarity (<10 yrs: $13 \%$ vs > 20 yrs $6 \%$ ), while older oncologists reported a global competence in all phases of the disease $(>20$ yrs $38 \%$ vs $<10$ yrs $26 \%)$. Concerning the definition of palliative care, younger oncologists were more prone to consider palliative cares as a treatment that has to be started precociously, together with oncologic active treatment (<10 yrs $11 \%$ vs $>20$ yrs $2 \%)$.

\section{Discussion}

There is clear evidence that early initiation of palliative care can significantly improve quality of life and potentially even survival in patients with cancer (4). It is the responsibility of the oncologist who is in charge of the patient to guarantee an early access to palliative care, to detect the symptoms carefully and take action for adequate control $(6 ; 9)$.

This is the first survey conducted by AIOM that explores the views of Italian medical oncologists in terms of SC and represent a very helpful tool to improve knowledge in the practice and attitudes of Italian oncologists in early integration of palliative care.

As much as $73 \%$ of the oncologists agree that the patient should take part in the decision-making of the treatment, yet just half of them address the issue of disease prognosis with the patient, and only a minority routinely verifies end-of-life wills with the patient. Over $90 \%$ are inclined to inform family members about the prognosis of the patient and $20 \%$ uses chemotherapy for symptoms control $(50 \%)$ or per family or patient requests $(19 \%)$ in second-line metastatic biliary tract cancer (an example of poorly chemosensitive type of cancer). This seems to be an issue not confined to Italy, and may be of concern to the entire oncologist community. Indeed, oncologists have been shown to be reluctant to give prognostic information for a number of reasons, the majority of which are misconceptions, such as the feeling that it would make people depressed and it would take away hope, or the belief that involvement of hospice or palliative care will reduce survival, or again, that talking about prognosis may not be culturally appropriate (10). In a previous Italian survey, results showed oncologists used correct terms in $90 \%$ of cases when informing on diagnosis and prognosis, but the same oncologists used "vague" or "no pertinent terms" in 92\% when discussing prognosis with patients with metastasis (11). The bottom line is that probably oncologists tend to avoid these discussions because they are hard to deal with (10). So it is no surprise that in a recent study in the setting of newly diagnosed metastatic lung or colorectal cancer treated with chemotherapy, patients did not report understanding that chemotherapy was not at all likely to be curative, possibly compromising the ability to make informed decisions (12). Also, this may explain why treatment is prescribed because requested so by patients and/or their families or because of the feeling that some oncologic treatment should be continued in spite of negligible benefits by a quarter of Italian oncologists. Actually, Italian oncologists' attitude seems to be still somewhat far from the "gold-standard" of shared decision-making, since about one fourth of Italian medical oncologists tend to make decisions without involving the patient, with such numbers differing from those from other European countries (i.e. the Netherlands) as it emerges from the Eureld Study (13). Undoubtedly, communication is the first medication of cancer patients, and realistic information about treatment options and the real benefits of chemotherapy must be offered to all patients in advanced stage of disease (14 - 16). This requires appropriate communication strategies to learn how to explain, in a realistic way, the purposes of care, the disease prognosis, and deal with the patient also advance directives of the end of life (17). Indeed, in a view of patient-centered care to which the majority of Italian oncologists agreed, adequate information plays a major part, and if patients are not informed of the evidence and possible 
benefits and risks of a treatment they cannot participate in the decision making process $(15 ; 17)$. The key elements for communication skills training in oncology have been published in a European position paper (18). Effective communication skills can be improved with training and transferred into a clinical setting having an enduring impact $(18 ; 19)$. Also, in this survey there appears to be a mismatch between the $50 \%$ of Italian oncologists that are ready to thoroughly inform the patient on the prognosis and $90 \%$ that are prepared to talk about this issue with the family - this is clearly a different handling than in other countries (20). This could reflect a cultural background, as well as a lack of training in communication skills that is strongly advocated by most medical oncologists.

As for competence in palliative medicine, most oncologists claim to be able to properly manage tumor-related symptoms, consider it as an integral part of their acquired skills during training, and agree that it should be the medical oncologist who guarantees palliative care in cancer patients. Nevertheless, only $20 \%$ of respondents stated they use in clinical practice to detect the extent of symptoms and monitor them over time, despite several tests have been validated also in the Italian language (21; 22). Symptoms screening of every patient is a key step that helps the implementation of SC. Symptoms should be assessed with validated instruments at baseline and regularly throughout treatment, with the aim of improving patient's quality of life (23).

Palliative care screening tool should be shared among oncologists and palliative care physicians, to identify patients with more complex needs for whom referral to a specialist provider is recommended (2; 24).

Italian medical oncologists agree that research in the SC setting should have as primary objective patient's quality of life, using the same tools validated for symptom's control during the trials (25). Yet, the description of a more comprehensive definition of quality of life (wellbeing physical, psychological, socioeconomics and spiritual) as resulted from the open questions, is shared by only $2 \%$ of oncologists. Actually, as is the case for other definitions in the area of supportive care, terms that are quite common in oncology do not have a clear and shared definition. This could represent a barrier to communication in both the clinical and research settings (26). In this view, studies leading to a more rigorous definition, for each type of tumor, of "clinical benefit" and "quality of life" which regards the living and psycho-physical condition of the patient are felt to be a priority.

With regard to the organizational aspects of SC, most oncologists recognize the Bruera integrated care model (in which the oncologists focus on the primary cancer disease, and collaborates closely with the interdisciplinary palliative care team to address the majority of the patient's physical, and psychological concerns) as the best model to take charge of the patient, but only $34 \%$ of respondents currently applies it. This can be explained by the fact that many Italian oncologists are involved themselves in the management of advanced-terminal illness (27), perhaps even compensating for the lack of palliative services. In fact, the limited availability of palliative care specialists in Italian hospitals makes it difficult to achieve SC as an integrated model, as reported in a previous survey of the Italian ESMO-DCs (28). This may also explain why $36 \%$ of respondents define the oncologist as a "global expert"(from prevention to death); with such percentage increasing among respondents of southern Italy $(40 \%)$ where the palliative care services are less common, and progressively increasing with the age of the respondents ( $26 \%$ for those under 10 years of practice, $38 \%$ between 10 and 20, and $40 \%$ among those who have more than 20 years of activity as oncologist), indicating a probable generational change in the competences attributed to medical oncologist

Sixty-tree percent of oncologists recognize that the advocated joint approach of SC can be realized through the creation of Palliative Care services within the Oncology Departments, and 34\% think that the integration between Oncology Units and palliative care services should take place through regular multidisciplinary meeting and patients discussion Such an early integration of SC could be systematically realized through a revision of the current organizational models for health care in Italy, since it requires a close collaboration between community-based and hospital services dedicated to cancer patients. In light of this, both oncologists and palliative physician are making an effort to shed the either/or mentality and the perception of palliative as end-of-life care (29). The main concerns of Italian medical oncologists regarding interaction with the palliative care teams, besides possible conflicts between professionals, are the loss of a decision-making role, and the possibility of introducing elements of confusion for the patients. Yet, some studies show that the majority of families referred to PC programs state that they would have preferred an earlier consultation (30). It has been postulated that the proper unit for measuring value in health care should include all services or activities that altogether contribute to satisfy a set of patient needs, which are determined by the patient's medical condition. In the setting of the complex medical 
condition, which is metastatic cancer, an early access to palliative care would provide value for health care (31). In fact, since value is measured by the outcomes achieved, and not by the volume of services delivered, shifting focus from volume to value is a central challenge (32).

Several limitations of the survey should be considered in the interpretation of these findings. The overall response rate of $40 \%$ medical oncologists is good, but it may not be generalised to the larger oncology community. Support for generalizability, however, comes from the similarity of responses for similar questions in previous national surveys (11; 17; 27 ), and the analogy in age, sex, and location distribution between responders and all AIOM members (AIOM data).

These limitations notwithstanding, the results of this nationwide survey suggest that there is at this time a large variation in setting and competence of oncologists across Italy. For this reason, different models of early integration of palliative care can be proposed, by sharing assessment tools and with low, intermediate or high level of integration, according to available resources and personal competences (6; 8; 23).

Individual groups and practices will need to structure their models to guarantee of SC application, based on their specific framework $(2 ; 7 ; 8 ; 23)$.

\section{Conclusions}

The activation of SC in clinical practice constitutes today one of the main topics to ensure quality of care and appropriate care setting for patients with advanced cancer disease. Although solo practice model, i.e. model A of Bruera (8), may be necessary or preferred in some cases, Italian oncologists agree that patients and families are best served by taking advantage of an integrated approach. Similarly, to other Countries (9), in addition to a shift in culture and adoption of effective models for service delivery, there are today some deficiencies in the workforce required to meet the palliative care needs in Italy.

Early introduction of palliative care in clinical practice results a work-in-progress, and it is likely that the inclusion of palliative care as a routine part of comprehensive cancer care for all cancer patients can be achieved before 2020, deadline suggested by ASCO.

Following the results of the questionnaires a national consensus conference was held in Rome (September 2013), and subsequently the AIOM position paper on SC has been defined (33).

Given the importance of the results of this survey, the AIOM board has also taken the following actions: 1 . Turn the Task Force into a permanent organ of AIOM, in order to monitor the development of SC in Italian Oncology Units; 2. Continue promotion of training of medical oncologists in palliative care, especially younger ones, in order to develop abilities to communicate bad news, and skills in symptom control by using validated tests as a part of clinical practice; 3. Maintain a close collaboration with ESMO-DCs to facilitate other Oncology Units to become ESMO-DCs; 4 . Activate a working group with Italian Society of Palliative Care, to share the taxonomy of the language of the SC and facilitate mutual understanding and integration between oncologists and palliative care team. 5. Take action on Institutions, with patients' advocacy, to be guaranteed the activation of early palliative care through the inclusion of palliative care services in the care pathways of cancer patients and in the all oncology departments.

\section{Supplementary Material}

Supplementary material $\mathrm{S1}$.

http://www.jcancer.org/v07p1968s1.pdf

\section{Acknowledgments}

We thank Giovanni Ratti (AIOM secretary) for the contribution to data entry and Kathleen Marie Hughes for English editing.

\section{Competing Interests} interest.

The authors have declared no conflicts of

\section{References}

1. [No authors listed]. Cancer care during the last phase of life. J Clin Oncol. 1998; 16:1986-96.

2. Glare PA. Early implementation of palliative care can improve patient outcomes. JNCCN. 2013, 11(suppl 11):S3-9

3. Ramchandran K, Von Roenn JH. Palliative Care Always. Oncology (Williston Park). 2013; 27(1): 1-18

4. Temel JS, Greer JA, Muzikansky A, Gallagher ER, Admane S, Jackson VA, et al. Early palliative care for patients with metastatic Non-Small-cell lung cancer. N Engl J Med. 2010; 363(8):733-42.

5. Cherny N, Catane R, Schrijvers D, et al. European Society for medical oncology (ESMO) program for the integration of oncology and palliative care: a 5-year review of the designated centers' incentive program. Ann Oncol. 2010; 21: 362-9.

6. Zagonel V, Cavanna L, Cetto G, et al. Task Force AIOM Palliative Care in Oncology. The medical oncologist's role in palliative care: AIOM's position. Tumori. 2009; 95:652-4.

7. Hui D, Kim YJ, Park JC, et al. Integration of Oncology and Palliative Care: A Systematic Review. Oncologist. 2015;20:77-83.

8. Bruera E, Hui D. Integrating supportive and palliative care in the trajectory of cancer: establishing goals and models of care. J Clin Oncol. 2010; 28: 4013-17.

9. Smith TJ, Temin S, Alesi ER, et al. American Society of Clinical Oncology provisional clinical opinion: the integration of palliative care into standard oncology care. J Clin Oncol. 2012; 30:880-7.

10. Mack JW, Smith TJ. Reason why physicians do not have discussions about poor prognosis, why it matters, and what can be improved. J Clin Oncol. 2012; 30:2715-7.

11. Gori S, Greco MT, Catania C, et al; AIOM Group for the Informed Consent in Medical Oncology. A new informed consent form model for cancer patients: preliminary results of a prospective study by the Italian Association of Medical Oncology (AIOM). Patient Educ Couns. 2012; 87:243-9.

12. Weeks JC, Catalano PJ, Cronin A, et al. Patients' expectations about effects of chemotherapy for advanced cancer. N Engl J Med. 2012; 367:1616-25. 
13. van der Heide A, Deliens L, Faisst K, et al. End-of-life decision-making in six European countries: descriptive study. Lancet. 2003; 362: 345-50.

14. Peppercorn JM, Smith TJ, Helft PR, et al. American Society of Clinical Oncology statement: toward individualized care for patients with advanced cancer. J Clin Oncol. 2011; 29:755-60.

15. Keating NL, Beth Landrum M, Arora NK, et al. Cancer patients' roles in treatment decisions: do characteristics of the decision influence roles? J Clin Oncol. 2010; 28:4364-70.

16. Temel JS, Greer JA, Admane S, et al. Longitudinal perceptions of prognosis and goals of therapy in patients with metastatic Non-Small-Cell Lung Cancer: Results of a randomized study of early palliative care. J Clin Oncol. 2011; 29:2319-26.

17. Catania C, Zagonel V, Fosser V, et al. Opinions concerning euthanasia, life-sustaining treatment and acceleration of death: results of an Italian Association of Medical Oncology (AIOM) survey. Ann Oncol. 2008; 19:1947-54.

18. Stiefel F, Barth J, Bensing J, et al. Communication skills training in oncology: a position paper based on a consensus meeting among European experts in 2009. Ann Oncol. 2010; 21:204-7.

19. Baile WF, Buckman R, Lenzi R, et al. SPIKES-A six-step protocol for delivering bad news: application to the patient with cancer. Oncologist. 2000; 5:302-11.

20. Hauke D, Reiter-Theil S, Hoster E, et al. The role of relatives in decisions concerning life-prolonging treatment in patients with end-stage malignant disorders: informants, advocates or surrogate decision-makers? Ann Oncol. 2011; 22:2667-74

21. Moro C, Brunelli C, Miccinesi G, et al. Edmonton symptom assessment scale: Italian validation in two palliative care settings. Support Care Cancer. 2006; 14:30-7.

22. Grassi L, Johansen C, Annunziata MA, et al. Italian Society of Psycho-Oncology Distress Thermometer Study Group. Screening for distress in cancer patients: a multicenter, nationwide study in Italy. Cancer. 2013;119:1714-21.

23. Partridge AH, Seah DS, King T, et al. Developing a service model that integrates palliative care throughout cancer care: the time is now. J Clin Oncol. 2014; 32:3330-6.

24. Carlson LE, Waller A, Mitchell AJ. Screening for distress and unmet needs in patients with cancer: review and recommendations. J Clin Oncol. 2012; 30:1160-77.

25. Zafar SY, Currow DC, Cherny N, et al. Consensus-based standards for best supportive care in clinical trials in advanced cancer. Lancet Oncol. 2012; 13(2):e77-82.

26. Hui D. Definition of supportive care: does the semantic matter? Curr Opin Oncol. 2014; 26: 372-9.

27. Barni S, Maltoni M, Tuveri G, et al. Attitude of Italian medical oncologists toward palliative care for patients with advanced cancer: results of the SIO project. Support Care Cancer. 2011; 19:381-9.

28. Zagonel V, Mastromauro C, Ciaparrone M, et al. Survey models of integration on oncology and palliative care (PC) in Italian oncology units ESMO designated centers. Ann Oncol. 2012; 23 suppl 9, abstract 1436P.

29. Davis M. Integrating palliative medicine into an oncology practice. Am J Hosp Palliat Care. 2005; 22:447-56.

30. Morita T, Miyashita M, Tsuneto S, et al. Late referrals to palliative care units in Japan: nationwide follow-up survey and effects of palliative care team involvement after the cancer control act. J Pain Symptom Manage. 2009; 38:191-6.

31. Parikh RB, Kirch RA, Smith TJ, Temel JS. Early specialty palliative care--translating data in oncology into practice. N Engl J Med. 2013; 369:2347-51.

32. Porter ME. What is value in health care? N Engl J Med. 2010; 363:2477-81.

33. [Internet] AIOM position paper on simultaneous care. http://www.aiom.it/aiom-servizi/eventi-aiom-servizi/consensus+conferenc e+simultanoeus+care $/ 1,1113,0$ 